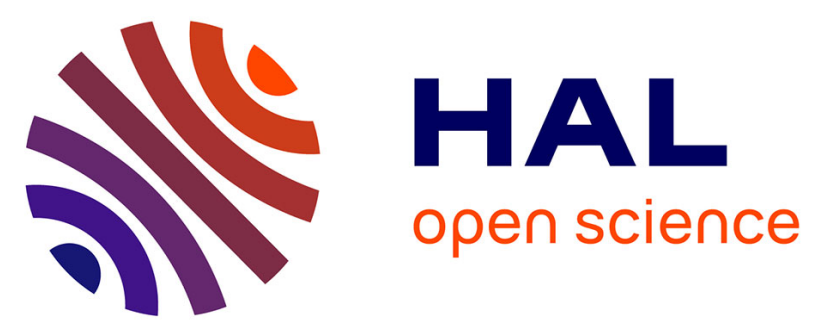

\title{
Cognitive complaints in cancer: the French version of the Functional Assessment of Cancer Therapy-Cognitive Function (FACT-Cog), normative data from healthy population French FACT-Cog normative data from a healthy population
}

Marie Lange, Natacha Heutte, Nastassja Morel, Francis Eustache, Florence Joly, Bénédicte Giffard

\section{- To cite this version:}

Marie Lange, Natacha Heutte, Nastassja Morel, Francis Eustache, Florence Joly, et al.. Cognitive complaints in cancer: the French version of the Functional Assessment of Cancer TherapyCognitive Function (FACT-Cog),normative data from healthy population French FACT-Cog normative data from a healthy population. Neuropsychological Rehabilitation, 2015, 26 (3), pp.392-409. 10.1080/09602011.2015.1036890 . inserm-01153316

\section{HAL Id: inserm-01153316 https://www.hal.inserm.fr/inserm-01153316}

Submitted on 19 May 2015

HAL is a multi-disciplinary open access archive for the deposit and dissemination of scientific research documents, whether they are published or not. The documents may come from teaching and research institutions in France or abroad, or from public or private research centers.
L'archive ouverte pluridisciplinaire HAL, est destinée au dépôt et à la diffusion de documents scientifiques de niveau recherche, publiés ou non, émanant des établissements d'enseignement et de recherche français ou étrangers, des laboratoires publics ou privés. 


\title{
Cognitive complaints in cancer: the French version of the Functional Assessment of Cancer Therapy-Cognitive Function (FACT-Cog),normative data from healthy population
}

\author{
French FACT-Cog normative data
}

Marie Lange ${ }^{1,2,3}, \mathrm{PhD}$, Natacha Heutte ${ }^{1,3}, \mathrm{PhD}$, Nastassja Morel $^{2}, \mathrm{PhD}$, Francis Eustache ${ }^{2}$, $\mathrm{PhD}$, Florence Joly ${ }^{1,3,4}$, MD, PhD, Bénédicte Giffard ${ }^{2}, \mathrm{PhD}$

Institutional Affiliations:

${ }^{1}$ Unité de Recherche Clinique, Centre François Baclesse, Caen, France

${ }^{2}$ INSERM, Normandie Université, CHU de Caen, EPHE, U1077,Caen, France

${ }^{3}$ INSERM, U1086, Caen, France

${ }^{4}$ CHU de Caen, Service d'Oncologie, Caen, France

Corresponding author :

Dr Bénédicte GIFFARD

Université de Caen Basse-Normandie, Esplanade de la Paix,

U.F.R. de Psychologie, 14032 Caen Cedex, France

Tel: (33)231566279 Fax: (33)231565665

benedicte.giffard@unicaen.fr 


\begin{abstract}
Cancer patients often report cognitive changes after chemotherapy.The Functional Assessment of Cancer Therapy-Cognitive Function (FACT-Cog) is a self-report questionnaire that assesses these changes.The aims of the present study were1) to establish normative data and 2) to compare the score of patients' and healthy controls' samplesto assess whether the questionnaire is able to discriminate between these populations.

The normative sample included 213 healthy participants. The patient group included 63 cancer patients treated with chemotherapy, who were compared to a subsample of 63 matched healthy controls.

The questionnaire had goodinternal consistency reliability(Cronbach's alphas: from 0.74 to 0.91). The oldest patients had significantly more cognitive complaints $(\mathrm{p}<0.001)$.Cognitive complaints were significantly related withTrail Making testscores $(\mathrm{p}<0.001)$. Furthermore, FACT-Cog subscales correlated significantly with anxiety and depression. Patients had more complaints than matched controls onthe subscalesPerceived Cognitive Impairments $(\mathrm{p}=0.01)$, Impact on Quality of Live $(\mathrm{p}=0.001)$ and Perceived Cognitive Abilities $(\mathrm{p}=0.027)$.

The reference values from the healthy population reported here could be used for comparison with the cognitive complaints measured in French-speaker cancer patients. It provides a benchmark against which clinicians could evaluate the impact of the disease and/or the treatments on cognitive complaints and helps to improve quality of life by providing appropriate care.
\end{abstract}

\title{
Keywords:
}

Cognitive complaints, Quality of Life, Cancer, Functional Assessment of Cancer Therapy (FACT), Normative data 


\section{Introduction}

Impairment of cognitive function is a common complaint in cancer patients receiving chemotherapy. According to a systematic review, 21 to $90 \%$ of breast cancer patients report subjective cognitive dysfunction (Pullens, De Vries, \& Roukema, 2010) concerning changes in their memory and attention, and difficulties with multi-tasking and making decisions about daily activities(Myers, 2013). Cognitive complaints are sometimes perceived a long time after treatment: 5 years after their adjuvant chemotherapy, $46 \%$ of patients still reported selfperceived cognitive deficits(Mehnert et al., 2007).This problem, commonly namedchemobrain or chemofog, has mostlybeen studiedin breast cancer patients andoccurs in 13 to $70 \%$ of patients receiving chemotherapy(Wefel, Vardy, Ahles, \& Schagen, 2011).Itmainly affects episodic memory, working memory, executive functions, attention, and information processing speed(Ahles, 2012).Though subtle, such cognitive deficits affect patients' quality of life(Von Ah, Habermann, Carpenter, \& Schneider, 2013; Reid-Arndt, Hsieh, \& Perry, 2010) and may reduce their ability to make a smooth transition from treatment back to daily activities(Nieuwenhuijsen, de, Spelten, Sprangers, \& Verbeek, 2009; Munir, Burrows, Yarker, Kalawsky, \& Bains, 2010).Furthermore, recent longitudinal studies have shown that about 20 to $30 \%$ of breast cancer patients have cognitive impairment before starting adjuvant treatment (Ahles, 2012).

Estimates of the frequency of post-chemotherapy cognitive change vary among studies, likely because of a methodological heterogeneitybetweenthem,such as criteria for defining change, assessment instruments used or comparison groups.

While cognitive functioning is usually measured objectively through neuropsychological tests,patient self-evaluation of cognitive difficulties is an important complement,all the more since,overall,a lack of relationship between subjective complaints and objective cognitive deficits has been found whereas subjective complaints were commonly associated with anxiety and depression(Hutchinson, Hosking, Kichenadasse, Mattiske, \& Wilson, 2012; Pullens et al., 2010). This lack of relationship among cancer patients may partly be explainedby compensatory mechanisms used to reduce the cognitive disturbances(Ferguson, McDonald, Saykin, \& Ahles, 2007; Janelsins et al., 2011). Further efforts or strategies could be used to mitigate the cognitive disturbances, hence the existence of complaints in the absence of objective cognitive impairment. It seems interesting to analyze the correlations between objective and subjective cognitive scores in healthy subjects (i.e. without cognitive impairment) to assess whether there is also a lack of relationship in this 
population, which calls into question the hypothesis of the effect of compensatory mechanisms.

Despite these discrepancies between objective and subjective measures, subjective complaints are important due to its significant impact on quality of life(Hutchinson et al., 2012). Moreover, during normal ageing, cognitive complaints increase(Mol et al., 2007). In this way, it is therefore necessaryand important to have comparative data in healthy controls for different age groups to assess accurately subjective cognitive functioning of cancer patients and to determine if the perceived impairments are associated with cancer and not only with ageing.Furthermore, there is a lack of published normative data on self-reporting cognitive questionnaires used in chemobrain research(Cheung, Tan, \& Chan, 2012).Indeed, in a study where there is no group of healthy subjects (i.e. subjects without cancer and neurological and psychiatric co-morbidity), it is very difficult to assess the importance of the cognitive complaints that are expressed by cancer patients. The same problem exists in clinical practice and normative data would permit to conclude to significant cognitive complaints.

While limited, intervention care for chemobrainexists(Léger, de Batz, \& Dauchy, 2013)such as cognitive training which has demonstrated evidence of enhancing objective cognitive performance (Von Ah, Storey, Jansen, \& Allen, 2013). In this perspective, properly assessed, cognitive complaints should permit to detect patients whosuffered fromchemobrain and to propose them adapted intervention care.

The Functional Assessment of Cancer Therapy-Cognitive Function (FACT-Cog) is the only self-report questionnaire which has specifically assessed cognition,developed from interviews with expert clinicians and oncology patient focus groups(Wagner, Sabatino, Cella, \& et al, 2005; Wagner, Sweet, Butt, Lai, \& Cella, 2009). Itis the first patient-reported outcomes measure evaluating cognitive impairment to be validated with cancer patients and can potentially be used in standard clinical practice as a tool for evaluating patients' cognitive complaints before, during and after chemotherapy. Quick to administer, it facilitates the assessment of patients' cognitive complaints and the impact of cognitive impairment on their quality of life. Various cognitive domains can be subjectively assessed: mental acuity, concentration, memory, verbal fluency, multi-tasking, interference and functional change. In addition, it assesses comments from others.As a complement to the validation with cancer patients previously published (Joly et al., 2012), in the present study the French version of the questionnairewasadministered to healthy individualsin order to establish normative data. We 
also compared cancer patients'and healthy controls' scores to assess whether the questionnaire is able to discriminate between these groups. Finally, relationships between FACT-Cog scores and objective cognitive performances, anxiety and depression in healthy sample were also investigated.

\section{Materials and Methods}

\section{$\underline{\text { Participants }}$}

Two hundred and thirteen healthy subjects were recruited through local advertisements and among associations. None had any cancer previous medical history and they had to be fluent in French. In addition, exclusion criteria were established for healthy controls: neurological co-morbidity, cognitive impairments as assessed with the Mini-Mental State Examination (MMSE)(Folstein, Folstein, \& McHugh, 1975), history of severe psychiatric or mental health problems, i.e. mood disorders such as depression, dysthymia, bipolar disorders, anxiety,posttraumatic stress disorder, panic attack, generalized anxiety disorder, schizophrenia and other psychotic disorders; permanent addictive pathology, or chronic painful illnesses with chronic morphine treatment.All healthy controls gave their written informed consent to participate.

In addition to this healthy sample, a group of sixty-three patients recruited during their outpatient chemotherapy at the day care hospital was also included. This is the same sample as in the article validating the French version of the FACT-Cog(Joly et al., 2012). Any adult cancer patient undergoing chemotherapy or having received at least two cycles of chemotherapy in the last 6 months was eligible to participate. Exclusion criteria were the same as in healthy controls and patients gave their written informed consent to participate in the study, which was conducted in accordance with the Declaration of Helsinki and approved by the local ethics committees.

\section{Functional Assessment of Cancer Therapy-Cognitive Function (FACT-Cog)}

The FACT-Cog version 3 is a 37-item Likert-scaled questionnaire with responses ranging from 0 to 4 andconsisting of four subscales. Higher scores represent better functioning or quality of life.According to FACT-Cog scoring guidelines, adding subscale scores to derive total scores is not applicable.

For each item of the Perceived Cognitive Impairments subscale (PCI: e.g., "I have had trouble concentrating", range: 0-72) the patient has to indicate how often the situation 
occurred during the last 7 days, on a 5-point Likert scale (from 0 "never" to 4 "several times a day"). In PCI subscale, negatively worded items (e.g., "My thinking has been slow") were reverse scored prior to summing items for the subscale scores, such that a higher score represents better functioning or quality of life.

For each item of the Comments From Others subscale (Oth: e.g., "Other people have told me I seemed confused”, range: 0-16), like for PCI subscale, the patient has to indicate how often the situation occurred during the last 7 days, on a 5-point Likert scale. In Oth subscale, like for PCI subscale, negatively worded items were reverse scored prior to summing items for the subscale scores.

When rating their Perceived Cognitive Abilities(PCA: e.g., "My memory is as good as it has always been", range: 0-28), the patientmust use a different 5-point Likert scale (from 0 "not at all" to 4 "very much").For this subscale, the scoring was not reversed.

Finally, for each item of the impact on Quality Of Lifesubscale (QoL: e.g., "These problems have interfered with my ability to work", range: 0-16), like for PCA subscale, the patient must use a different 5-point Likert scale (from 0 "not at all" to 4 "very much"). For QoL subscale, like for PCI and Oth subscales, negatively worded items were reverse scored prior to summing items for the subscale scores.

\section{Procedure}

Originally, healthy participants took part of one of 2 separate studies using a different depression scale or cognitive battery, but in each of these studies, the FACT-Cog was completed to compare the responses of healthy subjects to those of patients treated for cancer. Exclusion criteria of participants were the same in these 2 studies. Thus, the pooling of FACT-Cog data allowed having more strength in the statistical analyses.

Upon recruitment, participants completed a form with questions regarding demographic data, their previous medical history, and medications. The MMSE(Folstein et al., 1975), a brief measure of cognitive function, was administered to healthy participants aged 65 and more, and to patients aged 50 and over. Participants with an MMSE score of fewer than 26 out of 30 , which is indicative of possible pathological ageing, were excluded from the study(Crum, Anthony, Bassett, \& Folstein, 1993; Kalafat, Hugonot-Diener, \& Poitrenaudl, 2003).Eligible participants were asked to complete the FACT-Cog questionnaire.For healthy controls, depression was assessed with the Center for Epidemiologic Studies-Depression scale (CES-D) or the Beck Depression Inventory 
(BDI)(Radloff, 1977; Beck, Ward, Mendelson, Mock, \& Erbaugh, 1961) and anxiety with theSpielberger State-Trait Anxiety Inventory - STAI(Spielberger, 1983).

In addition, healthy participants underwent complementary objective cognitive assessment.The cognitive domains assessed are the most impaired among cancer patients treated by chemotherapy(Ahles, 2012), althoughnot all subjects weretestedwithexactly the same battery of neuropsychological tests. These measures were used to examine the relationship between objective and subjective cognitive scores in the healthy population. Episodic memory (Encoding Storage Retrieval- ESR(Eustache, Desgranges, \& Lalevee, 1998)), information processing speed (Trail Making test - TMT A(Reitan, 1958)), executive functions: reactive flexibility (TMT B(Reitan, 1958)) and spontaneous flexibility (verbal fluencies(Cardebat, Doyon, Puel, Goulet, \& Joanette, 1990)), short-term memory (digit span forward(Wechsler, 1997)), working memory (digit span backward, letter-number sequencing and arithmetic(Wechsler, 1997))and attention (d2(Brickenkamp, 1998))were assessed.

\section{$\underline{\text { Statistical methods }}$}

The internal consistency reliability of the FACT-Cog was assessed by measuring Cronbach's coefficient alphas on the 37 items of the questionnaire for each subscale.Values of 0.7 or greater are generally considered to be acceptable for group comparisons.In addition, non-parametric statistics were used to assess the effect of age, educationand sexgroups on the normative sample. Normative data were transformed into percentile scores. Finally, Spearman correlations were calculated to evaluate the associations between FACT-Cog scores and objective cognitive performances, anxietyand depression. Given the large number of correlation tests performed, a p-value $<0.01$ was considered in order to minimize type I error.Finally, non-parametric statistics were used to compare the FACT-Cog scores between the healthy control subsample and patients due in part to ceiling effects on the subscales QoL and Oth.

\section{Results}

$\underline{\text { Normative data (healthy participants) }}$

The normative sample consisted of 213 healthy participants. Mean age was 60.9 years $(\mathrm{SD}=11.6$, range $=35-89)$. To assess the effect of age, three age groups were considered: 30 - 
49 years $(\mathrm{n}=36) ; 50-69(\mathrm{n}=123)$; and $70-89(\mathrm{n}=54)$. The proportion of women was $86.8 \%$ (185 women and 28 men). To assess the effect of educational level, three education groups were considered: $\leq 7$ years $(n=32)$; between 8 and 12 years $(n=99) ; \geq 12$ years, which corresponds to the French high school degree $(n=82)$. The mean MMSE score $(n=140$, participants aged 65 and more $)$ was $28.6(\mathrm{SD}=1.2$, range $=26-30)$.

Owing to missing values, one observation was excluded from the analysisof internal consistency reliability for the PCI subscale.For the normative sample, Cronbach's alphas wereas follows: $\mathrm{PCI}=0.91, \mathrm{QOL}=0.88$, Oth $=0.74$, and $\mathrm{PCA}=0.90$, indicating a good reliability. To further assess the internal validity of the scale, the correlations between the four subscales were computed. The four subscales were significantly correlated with each other (Spearman correlation from0.31 to $0.63, p$ s $<0.0001$, exceptOth and QOL which had low a correlation: Spearman correlation $=0.15, \mathrm{p}=0.027$ ).

The mean and SD values of the FACT-Cog for each age, education and sexgroups are shown in Table 1.There was a significant effect of age for 2 of the 4 subscales of the questionnaire:on thePCI and PCA subscales, the oldestnormative sample had more cognitive complaints $(\mathrm{p}<0.001)$. Cognitive complaints were not significantly different according to education level ( $>>0.05)$. There was a significant effect of sexon 3 of the 4 subscales: for PCI, PCA and QoL subscales, women had more cognitive complaints than men $(p<0.01, p=0.037$, $\mathrm{p}=0.025$, respectively). However, the latter resultshould be considered with caution because there were few men in the normative sample and they were significantly younger than the women $(\mathrm{p}<0.001 ;$ means $=52.4$ vs. 62.1). Indeed, when age was considered as covariate, a significant effect of sex was showed only for QoL subscale $(\mathrm{p}=0.028)$.

As shown in Table 2, few FACT-Cog scores were significantly related with objective neuropsychological scores (9 significant correlations/44). The TMT A and B scores were significantly related with the PCI and PCA subscales $(\mathrm{p}<0.001)$. Moreover, Table 2also shows correlations between FACT-Cog scores and age, depression and anxiety. On the PCI and PCA subscales, all correlations were significant with age, anxiety and the two depression scores $(\mathrm{p}<0.001$ ) (except PCA and CES-D, p=0.53). The QoL subscale was significantly related only with anxiety and depression measures $(\mathrm{p}<0.001)$ and there was no significant correlation between the Oth subscale and these measures.

Considering thedifferences on the FACT-Cog scores according to age group, Table 3presentspercentiles for FACT-Cog subscales for the three age groups (percentile 5 to 90). 


\section{Comparison between matched control subsample and patients}

Sixty-three cancer patients were included. Mean age was 58.6 years $(\mathrm{SD}=11.9$, range = 36-79). Three age groups were considered: 30-49 years $(\mathrm{n}=16)$; 50-69 $(\mathrm{n}=24)$; and 70-89 $(\mathrm{n}=23)$. The proportion of women was $68.2 \%$ (43 women and 20 men). Three education groups were considered: $\leq 7$ years $(n=23)$; between 8 and 12 years $(n=25)$; $\geq 12$ years, which correspond to the French high school degree $(n=15)$. The mean MMSE score $(n=46)$ was $28.6(\mathrm{SD}=1.1$, range $=27-30)$.

The internal consistency reliabilityof the scale in the patients group is available in the validation article of the French FACT-Cog(Joly et al., 2012) $(\mathrm{PCI}=0.93$, QoL $=0.85$, Oth $=0.70, \mathrm{PCA}=0.89)$.

A selection of healthy controls taken from the normative sample presented above was compared to the patients. For this purpose, 63 controls were selected and carefully matched for age $($ mean $=57, \mathrm{SD}=11.4)$, education level, gender $(68.2 \%$ female $)$ and MMSE $($ mean $=$ 28.5, SD = 1.4) $($ Table 4).

The FACT-Cog scores on each of the four subscales are presented in Table 4.FACTCog scores were significantly higher inthe control groupon the PCI, QoLand PCAsubscales compared to patients, which means thathealthy participants hadfewer cognitive complaints ( $\mathrm{p}=0.01, \mathrm{p}=0.001, \mathrm{p}=0.027$, respectively). The Oth subscale scores did not differ significantly between the groups $(\mathrm{p}=0.19)$.

\section{Discussion}

The FACT-Cog questionnaireisthe first patient-reported outcomes measure evaluating cognitive complaints to be validated with cancer patients. Furthermore, it facilitates the assessment of patients' cognitive complaints and the impact of cognitive impairment on their quality of life.However, little data is available on the French version.

As a complement to the validation with cancer patients, the French version of the FACT-Cog wasadministered to healthy individuals in order to establish normative data for the comparison of perceived cognitive function in cancer patients and the healthy population (without cancer and neurological or psychiatric co-morbidity).With a lack of published 
normative data and without a group of healthy subjects, it is not possibleto assess the importance of the cognitive complaints that are expressed by cancer patients. The same problem exists in clinical practice and normative data would permit to conclude to significant cognitive complaints.The questionnaire had goodinternal consistency reliability in the normativesample(Cronbach's alphas: from 0.74 to 0.91 ).

Younger participants had fewer cognitive complaints than older participants. This significant effect of age was found on the two subscales assessing the patient's perceived cognitive functioning (PCI and PCA).Conversely,the subscales QoL or Oth(i.e. the impact of the cognitive impairment on quality of life and people's comments about cognitive impairment of the patient) did notseem to be related with age. In healthy individuals, many effects of age have been demonstrated on cognitive functioning (slowdown in processing speed(Salthouse, 1996), declines in inhibitory processing(Radvansky, Zacks, \& Hasher, 2005), decrease in performance related to working memory(De \& Palladino, 2004) and episodic memory(Clarys, Bugaiska, Tapia, \& Baudouin, 2009)) which could explain this increase of cognitive complaints.Anxio-depressive symptoms also increase with ageing, yet these symptoms arecommonly associated with cognitive complaints. Age effectshave been observed with other self-reported cognitive questionnaires in healthy subjects(e.g.(VallatAzouvi, Pradat-Diehl, \& Azouvi, 2012). Age is therefore an important parameter to be considered in studies assessing cognitive complaints. Thus, the percentiles for the four subscales were calculated for each age group $(30-49 ; 50-69 ; 70-89$ years). These data are necessary and important to assess accurately subjective cognitive functioning of cancer patients and to determine if the perceived impairments by elderly patients are associated with cancer and not simply with ageing.

The women in our sample reported more cognitive complaints that men (except on the subscale Oth). Nevertheless, if age effect is controlled, sex has an effect only on the subscale QoL. Cognitive difficulties may have a significant impact on women quality of life. Otherwise, results did not indicate any significant correlation between education level and FACT-Cog scores.

The normative sample included few participants in the younger age group (30-49) and many women. However, this large proportion of women and more precisely middle age women means that the healthy sample was more comparable to a population of breast cancer patients, population in which the chemobrain is the most studied. 
In healthy participants, overall, the FACT-Cog subscales were significantly correlated with emotional measures (anxiety and depression). On the other hand,few significant correlations were found between cognitive complaints and objective cognitive performances.Similar results have already been observed with the FACT-Cog questionnaire(Biglia et al., 2012; Jacobs, Jacobsen, Booth-Jones, Wagner, \& Anasetti, 2007; Vardy et al., 2006) and with other questionnaires of cognitive complaints among cancer patients(Berman et al., 2013; Castellon et al., 2004; Kesler et al., 2013).

Although, overall, a lack of relationship between subjective complaints and objective cognitive deficits has been found, the TMT A and B scores were significantly related with the PCI and PCA subscales. These results are consistent with others based on self-report questionnaire assessing cognitive complaints of cancer patients from four subscales specific to one cognitive domain; this suggests that subjective cognitive complaints in part reflect objective performance in domain-specific cognitive tests(Ganz et al., 2013).Indeed, cognitive complaint questionnaires like the FACT-Cog are usually multidimensional, i.e. they concern various cognitive domains. Thus, it is understandable why global measures cannot be related to each domain-specific neuropsychological test score.Moreover, our results did not confirm the hypothesis that the lack of relationship between subjective complaints and objective cognitive deficitsmay partly be explained by compensatory mechanisms used to reduce the cognitive disturbances(Ferguson et al., 2007; Janelsins et al., 2011). Indeed, even in the absence of cognitive impairment (i.e. among healthy participants), thus in a situation not requiring compensatory mechanisms, only two objective scores are related to cognitive complaints.

When compared to their matched controls, patients reported significantly more cognitive complaints on three of the four FACT-Cog subscales: PCI, QoL and PCA. The validity of the cognitive complaint assessment was examined by this ability to discriminate patients and controls. Only the subscale Comments from Othersdid not allow patients and healthy controls to be discriminated.Indeed, cancer-related cognitive impairments were usually not severe, thus the comments from others about patient cognitive dysfunctions could be rare. The subscale Comments from Others must not be used to accurately assess cognitive complaints of cancer patients. Nevertheless, the three other subscales can be used in studies to determine if complaints of patients' group are significant. Moreover, in clinical practice, with reference to these normative data, clinicians will know whether the patient hashigher 
cognitive complaints than slight complaints. All suspicious complaints will have to lead to a thorough neuropsychological assessment that should enable to propose adapted intervention care to patients.

The main limitation of the study is the small samples of patients and matched controls. Comparisons between these samples showed significant differences but a greater number of participantswould increase the power of the test. Furthermore, the normative sample has a low representativeness of general population: it includedfew participants in the age group 30-49 years and men, women volunteering more for neuropsychological study. However, this large proportion of women and more precisely middle age womenmeans that the healthy samplewasmore comparable to a population of breast cancer patients; population in which the chemobrain is the most studied.

To conclude, the reference values from the healthy population reported here can be used for comparison with the cognitive complaints measured in French-speaker cancer patients, in research trials or clinical practice. It provides a benchmark against which clinicians can evaluate the impact of the disease and/or treatments for cognitive complaints and helps to improve quality of life by providing appropriate care.

Acknowledgments The authors thank all the healthy controls and patients who gave their time to participate.

Conflict of Interest The authors have no conflicts of interest. 
Reference List

Ahles, T. A. (2012). Brain vulnerability to chemotherapy toxicities. Psycho-Oncology, $21,1141-1148$.

Beck, A. T., Ward, C. H., Mendelson, M., Mock, J., \& Erbaugh, J. (1961). An inventory for measuring depression. Archives of General Psychiatry, 4, 561-571.

Berman, M. G., Askren, M. K., Sook, J. M., Therrien, B., Peltier, S., Noll, D. C. et al. (2013). Pretreatment Worry and Neurocognitive Responses in Women With Breast Cancer. Health Psychology, 33, 222-231.

Biglia, N., Bounous, V. E., Malabaila, A., Palmisano, D., Torta, D. M., D'Alonzo, M. et al. (2012). Objective and self-reported cognitive dysfunction in breast cancer women treated with chemotherapy: a prospective study. European Journal of Cancer Care, 21, 485492.

Brickenkamp, R. (1998). The d2 test of attention. Hogrefe \& Huber Publishing.

Cardebat, D., Doyon, B., Puel, M., Goulet, P., \& Joanette, Y. (1990). [Formal and semantic lexical evocation in normal subjects. Performance and dynamics of production as a function of sex, age and educational level]. Acta Neurologica Belgica, 90, 207-217.

Castellon, S. A., Ganz, P. A., Bower, J. E., Petersen, L., Abraham, L., \& Greendale, G. A. (2004). Neurocognitive performance in breast cancer survivors exposed to adjuvant chemotherapy and tamoxifen. Journal of Clinical and Experimental Neuropsychology, 26, 955-969.

Cheung, Y. T., Tan, E. H., \& Chan, A. (2012). An evaluation on the neuropsychological tests used in the assessment of postchemotherapy cognitive changes in breast cancer survivors. Supportive Care in Cancer, 20, 1361-1375.

Clarys, D., Bugaiska, A., Tapia, G., \& Baudouin, A. (2009). Ageing, remembering, and executive function. Memory., 17, 158-168. 
Crum, R. M., Anthony, J. C., Bassett, S. S., \& Folstein, M. F. (1993). Populationbased norms for the Mini-Mental State Examination by age and educational level. JAMA : the Journal of the American Medical Association, 269, 2386-2391.

De, B. R. \& Palladino, P. (2004). Decline in working memory updating through ageing: intrusion error analyses. Memory., 12, 75-89.

Eustache, F., Desgranges, B., \& Lalevee, C. (1998). [Clinical evaluation of memory]. Rev Neurol.(Paris), 154 Suppl 2, S18-S32.

Ferguson, R. J., McDonald, B. C., Saykin, A. J., \& Ahles, T. A. (2007). Brain structure and function differences in monozygotic twins: possible effects of breast cancer chemotherapy. Journal of Clinical Oncology, 25, 3866-3870.

Folstein, M. F., Folstein, S. E., \& McHugh, P. R. (1975). "Mini-mental state". A practical method for grading the cognitive state of patients for the clinician. J Psychiatr Res, 12, 189-198.

Ganz, P. A., Kwan, L., Castellon, S. A., Oppenheim, A., Bower, J. E., Silverman, D. H. et al. (2013). Cognitive complaints after breast cancer treatments: examining the relationship with neuropsychological test performance. Journal of the National Cancer Institute, 105, 791-801.

Hutchinson, A. D., Hosking, J. R., Kichenadasse, G., Mattiske, J. K., \& Wilson, C. (2012). Objective and subjective cognitive impairment following chemotherapy for cancer: a systematic review. Cancer Treatment Reviews, 38, 926-934.

Jacobs, S. R., Jacobsen, P. B., Booth-Jones, M., Wagner, L. I., \& Anasetti, C. (2007). Evaluation of the functional assessment of cancer therapy cognitive scale with hematopoietic stem cell transplant patients. Journal of Pain and Symptom Management, 33, 13-23.

Janelsins, M. C., Kohli, S., Mohile, S. G., Usuki, K., Ahles, T. A., \& Morrow, G. R. (2011). An update on cancer- and chemotherapy-related cognitive dysfunction: current status. Seminars in Oncology, 38, 431-438. 
Joly, F., Lange, M., Rigal, O., Correia, H., Giffard, B., Beaumont, J. L. et al. (2012). French version of the Functional Assessment of Cancer Therapy-Cognitive Function (FACTCog) version 3. Supportive Care in Cancer, 20, 3297-3305.

Kalafat, M., Hugonot-Diener, L., \& Poitrenaudl, J. (2003). [French standardization of the "Mini Mental State" (MMS) GRECO version]. Revue de neuropsychologie, 13(2), 209236.

Kesler, S., Hadi Hosseini, S. M., Heckler, C., Janelsins, M., Palesh, O., Mustian, K. et al. (2013). Cognitive training for improving executive function in chemotherapy-treated breast cancer survivors. Clinical Breast Cancer, 13, 299-306.

Léger, I., de Batz, L., \& Dauchy, S. (2013). [A memory consultation in oncology: between complaint and disorder...]. Psycho-Oncologie, 7, 210-216.

Mehnert, A., Scherwath, A., Schirmer, L., Schleimer, B., Petersen, C., SchulzKindermann, F. et al. (2007). The association between neuropsychological impairment, selfperceived cognitive deficits, fatigue and health related quality of life in breast cancer survivors following standard adjuvant versus high-dose chemotherapy. Patient Education and Counseling, 66, 108-118.

Mol, M., Carpay, M., Ramakers, I., Rozendaal, N., Verhey, F., \& Jolles, J. (2007). The effect of perceived forgetfulness on quality of life in older adults; a qualitative review. International Journal of Geriatric Psychiatry, 22, 393-400.

Munir, F., Burrows, J., Yarker, J., Kalawsky, K., \& Bains, M. (2010). Women's perceptions of chemotherapy-induced cognitive side affects on work ability: a focus group study. Journal of Clinical Nursing, 19, 1362-1370.

Myers, J. S. (2013). Cancer- and chemotherapy-related cognitive changes: the patient experience. Seminars in Oncology Nursing, 29, 300-307.

Nieuwenhuijsen, K., de, B. A., Spelten, E., Sprangers, M. A., \& Verbeek, J. H. (2009). The role of neuropsychological functioning in cancer survivors' return to work one year after diagnosis. Psycho-Oncology, 18, 589-597. 
Pullens, M. J., De Vries, J., \& Roukema, J. A. (2010). Subjective cognitive dysfunction in breast cancer patients: a systematic review. Psycho-Oncology, 19, 1127-1138.

Radloff, L. S. (1977). The CES-D Scale: A self-report depression scale for research in the general population. Applied Psychological Measurement, 1, 385-401.

Radvansky, G. A., Zacks, R. T., \& Hasher, L. (2005). Age and inhibition: the retrieval of situation models. The Journals of Gerontology.Series B, Psychological Sciences and Social Sciences, 60, 276-278.

Reid-Arndt, S. A., Hsieh, C., \& Perry, M. C. (2010). Neuropsychological functioning and quality of life during the first year after completing chemotherapy for breast cancer. Psycho-Oncology, 19, 535-544.

Reitan, R. (1958). Validity of trail making tests as an indicator of organic brain damage. Perceptual \& Motor Skills, 8, 271-276.

Salthouse, T. A. (1996). The processing-speed theory of adult age differences in cognition. Psychological Review, 103, 403-428.

Spielberger, S. D. (1983). Manual for the State-Trait Anxiety Inventory (STAI). Palo ALto, CA: Consulting Psychologists Press.

Vallat-Azouvi, C., Pradat-Diehl, P., \& Azouvi, P. (2012). The Working Memory Questionnaire: a scale to assess everyday life problems related to deficits of working memory in brain injured patients. Neuropsychological Rehabilitation, 22, 634-649.

Vardy, J., Wong, K., Yi, Q. L., Park, A., Maruff, P., Wagner, L. et al. (2006). Assessing cognitive function in cancer patients. Supportive Care in Cancer, 14, 1111-1118.

Von Ah, D., Habermann, B., Carpenter, J. S., \& Schneider, B. L. (2013). Impact of perceived cognitive impairment in breast cancer survivors. European Journal of Oncology Nursing, 17, 236-241.

Von Ah, D., Storey, S., Jansen, C. E., \& Allen, D. H. (2013). Coping strategies and interventions for cognitive changes in patients with cancer. Seminars in Oncology Nursing, 29, 288-299. 
Wagner, L. I., Sabatino, T., Cella, D., \& et al (2005). Cognitive function during cancer treatment: The FACT-Cog Study. The Journal of the Robert H.Lurie Comprehensive Cancer Center of Northwestern University, X, 10-15.

Wagner, L. I., Sweet, J., Butt, Z., Lai, J. S., \& Cella, D. (2009). Measuring Patient Self-Reported Cognitive Function: Development of the Functional Assessment of Cancer Therapy-Cognitive Function Instrument. The Journal of Supportive Oncology, 7, W32-W39.

Wechsler, D. (1997). Wechsler Adult Intelligence Scale-III. San Antonio: The Psychological Corporation.

Wefel, J. S., Vardy, J., Ahles, T., \& Schagen, S. B. (2011). International Cognition and Cancer Task Force recommendations to harmonise studies of cognitive function in patients with cancer. The Lancet.Oncology, 12, 703-708. 
Table 1 FACT-Cog subscale scores of normative sample $(n=213)$

\begin{tabular}{|c|c|c|c|c|c|}
\hline & & $\begin{array}{l}\text { Normative } \\
\text { ample }\end{array}$ & & & $\begin{array}{l}\text { Kruskal-Wallis } \\
\text { or Wilcoxon }\end{array}$ \\
\hline & & Mean (SD) & Median & Range & $\mathrm{p}$ value \\
\hline PCI (0-72) & & $59.3(9.2)$ & 61 & $28-72$ & \\
\hline Age group (years) & $\begin{array}{l}30-49 \\
50-69 \\
70-89\end{array}$ & $\begin{array}{l}63.3(6.1) \\
59.8(9.3) \\
55.5(9.4)\end{array}$ & $\begin{array}{c}64 \\
62 \\
57.5\end{array}$ & $\begin{array}{l}44-72 \\
28-72 \\
32-72\end{array}$ & $<0.001$ \\
\hline Years of schooling & $\begin{array}{c}\leq 7 \text { years } \\
>8 \text { and }<12 \text { years } \\
\geq 12 \text { years }\end{array}$ & $\begin{array}{c}58.9(9.6) \\
60.6(8.1) \\
58.0(10.1)\end{array}$ & $\begin{array}{c}61 \\
62 \\
60.5\end{array}$ & $\begin{array}{l}35-72 \\
34-72 \\
28-72\end{array}$ & 0.21 \\
\hline Sex & $\begin{array}{c}\text { Men } \\
\text { Women }\end{array}$ & $\begin{array}{l}63.6(7.4) \\
58.7(9.2)\end{array}$ & $\begin{array}{l}65 \\
61\end{array}$ & $\begin{array}{l}42-72 \\
28-72\end{array}$ & 0.003 \\
\hline QoL (0-16) & & $13.6(3.2)$ & 15 & $0-16$ & \\
\hline Age group (years) & $\begin{array}{l}30-49 \\
50-69 \\
70-89\end{array}$ & $\begin{array}{l}14.1(3.3) \\
13.4(3.5) \\
13.7(2.5)\end{array}$ & $\begin{array}{l}16 \\
15 \\
14\end{array}$ & $\begin{array}{l}4-16 \\
0-16 \\
7-16\end{array}$ & 0.11 \\
\hline Years of schooling & $\begin{array}{c}\leq 7 \text { years } \\
>8 \text { and }<12 \text { years } \\
\geq 12 \text { years }\end{array}$ & $\begin{array}{l}13.0(3.8) \\
13.5(3.5) \\
13.9(2.6)\end{array}$ & $\begin{array}{l}14.5 \\
15 \\
15\end{array}$ & $\begin{array}{l}0-16 \\
0-16 \\
5-16\end{array}$ & 0.60 \\
\hline Sex & $\begin{array}{c}\text { Men } \\
\text { Women }\end{array}$ & $\begin{array}{l}14.9(1.7) \\
13.4(3.4)\end{array}$ & $\begin{array}{l}16 \\
15\end{array}$ & $\begin{array}{c}10-16 \\
0-16\end{array}$ & 0.025 \\
\hline Oth $(0-16)$ & & $15.4(1.2)$ & 16 & $9-16$ & \\
\hline Age group (years) & $\begin{array}{l}30-49 \\
50-69 \\
70-89\end{array}$ & $\begin{array}{l}15.7(0.6) \\
15.4(1.3) \\
15.4(1.3)\end{array}$ & $\begin{array}{l}16 \\
16 \\
16\end{array}$ & $\begin{array}{c}14-16 \\
9-16 \\
10-16\end{array}$ & 0.68 \\
\hline Years of schooling & $\begin{array}{c}\leq 7 \text { years } \\
>8 \text { and }<12 \text { years } \\
\geq 12 \text { years }\end{array}$ & $\begin{array}{l}15.0(1.8) \\
15.5(1.3) \\
15.5(0.8)\end{array}$ & $\begin{array}{l}16 \\
16 \\
16\end{array}$ & $\begin{array}{c}9-16 \\
9-16 \\
11-16\end{array}$ & 0.16 \\
\hline Sex & $\begin{array}{l}\text { Men } \\
\text { Women }\end{array}$ & $\begin{array}{l}15.5(0.9) \\
15.4(1.3)\end{array}$ & $\begin{array}{l}16 \\
16\end{array}$ & $\begin{array}{c}12-16 \\
9-16\end{array}$ & 0.88 \\
\hline PCA $(0-28)$ & & $19.7(4.6)$ & 20 & $4-28$ & \\
\hline Age group (years) & $\begin{array}{l}30-49 \\
50-69 \\
70-89\end{array}$ & $\begin{array}{l}22.4(3.4) \\
19.7(4.7) \\
18.1(4.3)\end{array}$ & $\begin{array}{c}21.5 \\
20 \\
18\end{array}$ & $\begin{array}{l}16-28 \\
4-28 \\
8-27\end{array}$ & $<0.001$ \\
\hline Years of schooling & $\begin{array}{c}\leq 7 \text { years } \\
>8 \text { and }<12 \text { years } \\
>12 \text { years }\end{array}$ & $\begin{array}{l}19.3(4.3) \\
19.5(5.2) \\
20.2(4.0)\end{array}$ & $\begin{array}{l}19 \\
20 \\
20\end{array}$ & $\begin{array}{l}12-28 \\
4-28 \\
11-27\end{array}$ & 0.59 \\
\hline Sex & $\begin{array}{c}\text { Men } \\
\text { Women }\end{array}$ & $\begin{array}{l}21.1(5.6) \\
15.5(4.4)\end{array}$ & $\begin{array}{c}22.5 \\
20\end{array}$ & $\begin{array}{l}4-28 \\
7-28\end{array}$ & 0.037 \\
\hline
\end{tabular}

PCI: Perceived Cognitive Impairment, PCA: Perceived cognitive abilities, QoL: Impact on Quality of Life, Oth: Comments from others. A higher score represents better quality of life.

30-49 years: $n=36 ; 50-69: n=123$; and 70-89: $n=54$. Years of schooling: $\leq 7: n=32 ;>8$ and $<12$ : $\mathrm{n}=99 ; \geq 12: \mathrm{n}=82 ; 185$ women and 28 men. 
Table 2 FACT-Cog correlations with neuropsychological performances, age, depression and anxiety scores of normative sample

\begin{tabular}{|c|c|c|c|c|c|c|c|c|c|c|c|}
\hline \begin{tabular}{|c|} 
NP \\
Scores \\
FACT \\
Cog
\end{tabular} & $\begin{array}{c}\text { ESR } \\
\text { SE/FR } \\
(n=137)\end{array}$ & $\begin{array}{c}\text { ESR } \\
\text { DE/FR } \\
(n=137)\end{array}$ & $\begin{array}{c}\text { TMT A } \\
\text { time } \\
(n=213)\end{array}$ & $\begin{array}{c}\text { TMT B } \\
\text { time } \\
(n=213)\end{array}$ & $\begin{array}{c}\text { Digit span } \\
\text { forward } \\
(n=165)\end{array}$ & $\begin{array}{c}\text { Digit span } \\
\text { backward } \\
(n=165)\end{array}$ & $\begin{array}{c}\mathrm{D}^{\mathrm{a}} \\
(\mathrm{n}=56)\end{array}$ & $\begin{array}{c}\text { Verbal } \\
\text { fluencies } \\
\text { category } \\
(\mathrm{n}=125)\end{array}$ & $\begin{array}{c}\text { Verbal } \\
\text { fluencies } \\
\text { letter } \\
(\mathrm{n}=125)\end{array}$ & $\begin{array}{l}\text { Arithmetic } \\
(n=125)\end{array}$ & $\begin{array}{c}\text { Letter- } \\
\text { number } \\
\text { sequencies } \\
(\mathrm{n}=125)\end{array}$ \\
\hline PCI & $0.23^{*}$ & 0.13 & $-0.26^{* *}$ & $-0.23^{* *}$ & 0.002 & 0.17 & 0.22 & 0.14 & 0.12 & 0.17 & 0.12 \\
\hline QoL & -0.04 & 0.20 & -0.07 & -0.13 & -0.05 & 0.08 & -0.09 & 0.18 & 0.10 & 0.12 & 0.01 \\
\hline Oth & 0.20 & 0.08 & -0.10 & -0.10 & 0.01 & 0.01 & -0.03 & 0.04 & -0.08 & 0.004 & -0.05 \\
\hline \multirow[t]{2}{*}{ PCA } & 0.20 & 0.18 & $-0.30 * *$ & $-0.32 * *$ & 0.01 & $0.31 * *$ & 0.20 & $0.31 * *$ & 0.08 & $0.35^{* *}$ & $0.23 *$ \\
\hline & Age & $\begin{array}{c}\text { Depression } \\
\text { CES-D } \\
(\mathrm{n}=88)\end{array}$ & $\begin{array}{c}\text { Depression } \\
\text { BDI }(\mathrm{n}=125 \\
)\end{array}$ & \begin{tabular}{|c} 
Anxiety \\
STAI \\
State $(n=21$ \\
$3)$
\end{tabular} & & & & & & & \\
\hline PCI & $-0.34 * *$ & $-0.33 * *$ & $-0.42 * *$ & $-0.29 * *$ & & & & & & & \\
\hline QoL & -0.16 & $-0.43 * *$ & $-0.30 * *$ & $-0.35^{* *}$ & & & & & & & \\
\hline Oth & -0.05 & -0.10 & -0.13 & -0.12 & & & & & & & \\
\hline PCA & $-0.38 * *$ & -0.06 & $-0.44 * *$ & $-0.27 * *$ & & & & & & & \\
\hline
\end{tabular}

NP: Neuropsychological, ESR: Encoding Storage Retrieval, TMT: Trail Making test, SE: Superficial Encoding, DE: Deep Encoding, FR: Free Recall, PCI

Perceived Cognitive Impairment, QoL: Impact on Quality of Life, Oth: Comments from others, PCA: Perceived cognitive abilities. *p $<0.01$, ** $<<0.001$

${ }^{\mathrm{a}} \mathrm{D} 2$ : number of signs screened - number of errors 
Table 3 Percentiles on FACT-Cog subscales for each age group in normative sample

\begin{tabular}{|c|c|c|c|c|}
\hline Age group [30 - 49] $(n=36)$ & PCI & QoL & Oth & PCA \\
\hline 90 & 70 & 16 & 16 & 27 \\
\hline 80 & 68 & 16 & 16 & 26 \\
\hline 70 & 66 & 16 & 16 & 25 \\
\hline 60 & 65 & 16 & 16 & 24 \\
\hline 50 & 64 & 16 & 16 & 21 \\
\hline 40 & 63 & 16 & 16 & 21 \\
\hline 30 & 62 & 15 & 16 & 21 \\
\hline 20 & 60 & 12 & 15 & 19 \\
\hline 10 & 59 & 8 & 15 & 18 \\
\hline 5 & 47 & 6 & 14 & 16 \\
\hline Age group [50 - 69] $(n=123)$ & PCI & QoL & Oth & PCA \\
\hline 90 & 70 & 16 & 16 & 26 \\
\hline 80 & 67 & 16 & 16 & 24 \\
\hline 70 & 66 & 16 & 16 & 22 \\
\hline 60 & 64 & 16 & 16 & 21 \\
\hline 50 & 62 & 15 & 16 & 20 \\
\hline 40 & 59 & 14 & 16 & 19 \\
\hline 30 & 57 & 13 & 15 & 18 \\
\hline 20 & 51 & 11 & 15 & 16 \\
\hline 10 & 47 & 9 & 15 & 13 \\
\hline 5 & 43 & 6 & 12 & 11 \\
\hline Age group [70 - 89] $(n=54)$ & PCI & QoL & Oth & PCA \\
\hline 90 & 65 & 16 & 16 & 24 \\
\hline 80 & 63 & 16 & 16 & 22 \\
\hline 70 & 61 & 16 & 16 & 21 \\
\hline 60 & 60 & 15 & 16 & 19 \\
\hline 50 & 57 & 14 & 16 & 18 \\
\hline 40 & 55 & 14 & 16 & 18 \\
\hline 30 & 53 & 13 & 15 & 16 \\
\hline 20 & 49 & 12 & 15 & 14 \\
\hline 10 & 41 & 10 & 14 & 13 \\
\hline 5 & 36 & 8 & 13 & 9 \\
\hline
\end{tabular}

PCI: Perceived Cognitive Impairment (range: 0-72), QoL: Impact on Quality of Life (range: 0-16), Oth: Comments from others(range: 0-16), PCA: Perceived cognitive abilities (range: 0-28) 
Table 4 Description of patients and matched controls sample (healthy controls: $n=63$, patients: $n=63$ ) and comparison of FACT-Cog scores between samples

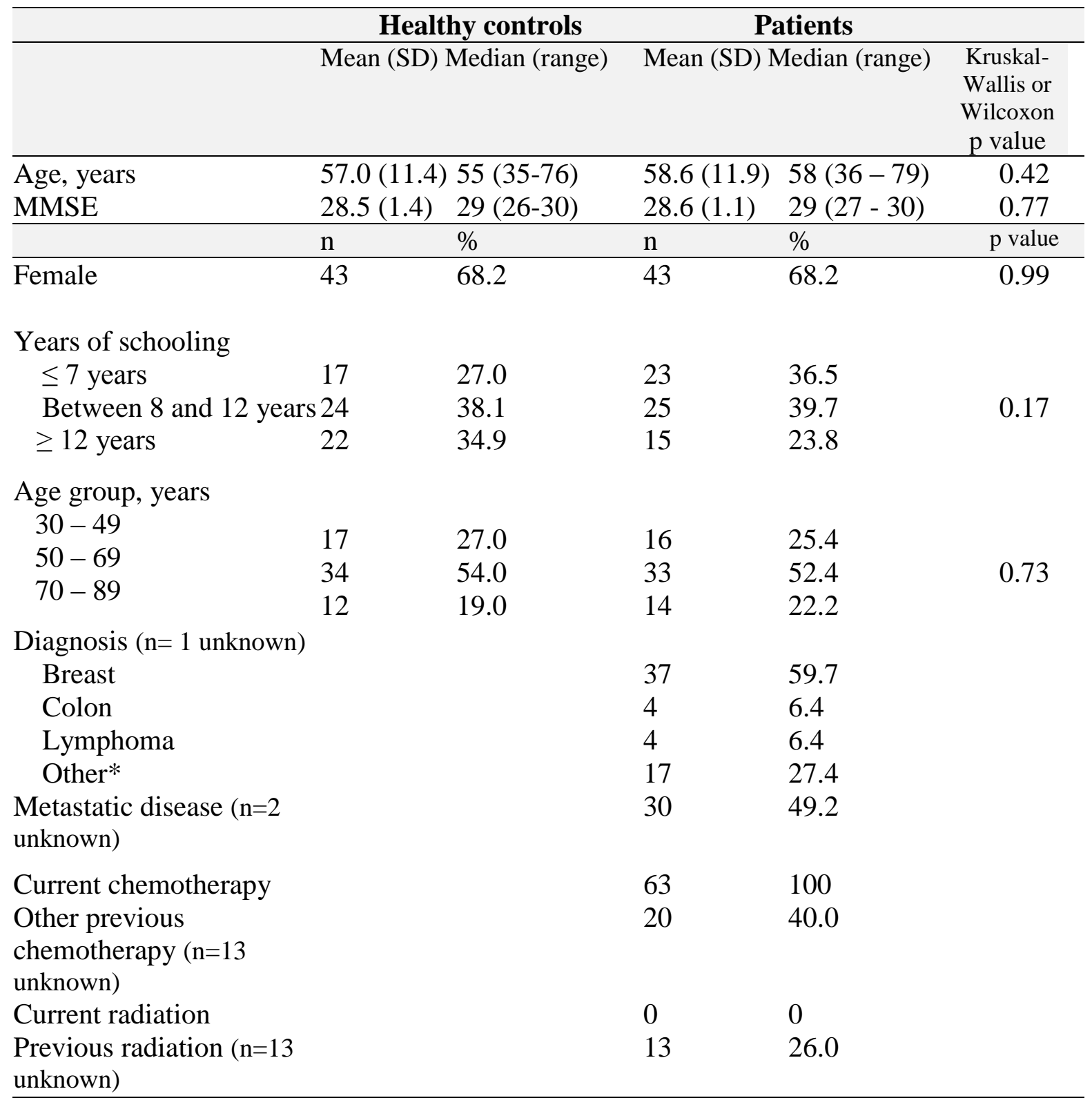
unknown)

Healthy controls

Patients

\begin{tabular}{cllllc}
\hline FACT-Cog subscales & Mean (SD) & Median (range) & Mean (SD) & Median (range) & p value \\
& & & & & \\
\hline PCI & $61.3(8.5)$ & $63(32-72)$ & $56.6(11.2)$ & $59(26-72)$ & 0.01 \\
QOL & $13.9(2.8)$ & $15(4-16)$ & $11.7(4.2)$ & $13(0-16)$ & 0.001 \\
Oth & $15.4(1.2)$ & $16(10-16)$ & $15.1(1.4)$ & $16(11-16)$ & 0.19 \\
PCA & $20.1(4.8)$ & $20(4-28)$ & $18.2(5.2)$ & $19(5-27)$ & 0.027 \\
\hline
\end{tabular}

PCI: Perceived Cognitive Impairment, QoL: Impact on Quality of Life, Oth: Comments from others, PCA: Perceived cognitive abilities

*Other diagnoses included: caecum, Hodgkin's, lung, myeloma, ENT, ovary, peritoneum, prostate, rectum, sigmoid, Waldenström.

A higher score represents better functioning or quality of life. 
